\title{
O direito dos livres docentes á regencia das cadeiras do curso de doutorado $\left({ }^{1}\right)$
}

\author{
Waldemar Ferreira
}

1. Por efeito de concurso, realisado em outubro de 1929, foi o Dr. Haroldo Teixeira Valladão, em 20 de fevereiro de 1930, nomeado docente livre de Direito Privado Internacional da Faculdade de Direito da Universidade do Rio de Janeiro.

E mercê dessa nomeação passou logo, no mês seguinte, a reger aquela cadeira, em substituição ao respetivo catedratico, o professor Rodrigo Octavio, que se licenciara.

1. Tomando conhecimento do mandado de segurança n. 106, * Côrte Suprema concedeu-o, pelo seguinte acordão:

"Vistos, relatados e discutidos estes autos de recurso de mandado de segurança n. 106, do Distrito Federal, que são recorrente o Dr. Haroldo Teixeira Valladão e recorrido o Conselho Universitario, acórdão em Côrte Suprema dar provimento ao recurso para, reformanco a decisão recorrida, conceder o mandado de segurança impetrado. E essa concessão é para o recorrente, como docente livre de Direito Privado Internacional, da Faculdade de Direito da Universidade do Rio de Janeiro, subsitituir o catedratico aposentado professor RoDRigo OcTAvio, assumindo interinamente a regencia da mesma cadeira até ser ela provida, tudo na conformidade com os votos proferidos e constantes das notas taquigraficas juntas, pagas as custas na fórma legal.

Rio, 29 de julho de 1935 (data do julgamento). - E. LiNs, Presidente. - LAUdo dE Camargo, Relator".

Assim decorreram os debates, qual se lé no Arquivo Judiciario, do Rio de Janeiro, vol. 35, pag. 408:

"O Sr. Ministro laudo De Camargo (Relator - 0 Dr. Ha. roldo VAlladão é docente livre de Direito Privado Internacional da 
2. Vigorava, a esse tempo, o dec. n. 16.782-A, de 13 de janeiro de 1925.

Constituindo o corpo docente dos institutos de ensino superior e secundario de professores catedraticos, docentes livres, professores honorarios, professores privativos e professores de desenho e de ginastica, estabeleceu aquele decreto, em termos muito claros, os direitos e as obrigações de cada um.

Colocou o decreto, como bem se vê, o docente livre logo depois do professor catedratico, por ter tido a preocupação de faze-lo o natural e obrigatorio substituto deste, supridos, como foram, os professores substitutos, com tal função, mas com direito de successão á cadeira, em caso de vaga.

Ficou isso bem claro no texto.

3. Obtinha-se o titulo de docente livre mediante concurso, prestado perante a Congregação e em tres provas desdobrado. A apresentação de uma tese, de livre escolha, e sua defesa por via de arguição por comissão examinadora que lhe apontaria os erros e solicitaria explicações sobre pontos obscuramente tratados, fazendo sobressair as contribuições originais, novas ou simplesmente bem expostas, dando margem para a demonstração, por parte do candidato, de intelligencia e preparo especialisado. Uma prova pra-

Faculdade de Direito da Universidade do Rio de Janeiro. Conquistou o titulo por concurso e veiu a ser nomeado em 20 de fevereiro de 1930. Logo em março desse ano, mediante designação, regeu a cadeira, por se haver licenciado o respetivo catedratico, Professor Rodrigo Octavio.

Mais tarde, com a refórma de 31 , o ensino do direito passou a ser ministrado em dois cursos: de bacharelado e de doutorado. A cadeira em questão veiu a sair daquele curso e a ser colocado neste. $E$ figurando no curso de doutorado passou a funccionar no $20^{\circ}$ ano da 1." sesção. Equivale a dizer que só funcionaria em 32 , como aconteceu.

Nesse ano, regeu-a o recorrente, como substituto do professor licenciado e mais tarde foi novamente indicado á regencia. Aconteceu, porém, que, em 34, a designação veiu a ser feita ao professor de Direito Publico Internacional, Raul Pederneiras. Isto deu motivo a uma reclamação, atendida pelo Conselho Universitario.

Continuou assim a regencia do recorrente.

Esta era a situação quando ainda veiu a ser alterada em abril deste ano, com a nova designação do Professor Pederneiras. 
tica, quando a natureza da disciplina exigisse. E uma dissertação durante cincoenta minutos, verbalmente, sobre ponto sorteado com antecedencia de vinte e quatro horas.

O concurso de livre docencia e seu julgamento obedeciam ás regras do para professor catedratico, com a diferença de exigencia, neste, de mais uma dissertação escrita sobre assunto sorteado.

Não era o concurso, em tais condições, méra formalidade: exigia-se nele e para ele quasi as mesmas provas e requisitos que para o professorado catedratico.

Arrostavam-no, em regra, os de solido e real preparo tecnico e especialisado, muito mais que os aventureiros, quasi sempre infelizes em justas de tal quilate. Tomavam sobre si os onus e as dificuldades a vencer, mais por vocação para o magisterio secundario e superior do que pelas vantagens imediatas da vitoria nele alcançada. Pretenção da lei foi a de, com a instituição da docencia livre, não somente dar estimulo aos moços de reconhecida competencia, senão, e principalmente, a de dar aos institutos de ensino superior e secundario professores substitutos dos catedraticos, sempre a postos para que não sofresse o ensino solução de continuidade, mas gratuitamente. Percebiam eles, então como

Daí o aparecer o Dr. Valladão perante a justiça, pedindo amparo ao seu direito lesado.

Dou-lhe razão e não vejo mesmo como se possa nega-lo, tão precisos se mostram os textos legais sobre a materia.

A sentença do ilustre juiz da $2 .^{2}$ vara negou a medida requerida, por entender que, no curso de doutorado, o que se pode ver é mais uma comissão, sem catedras e docencias livres, sendo os professores chamados pela Congregação dentre as catedraticos de bacharelado.

Penso diferentemente.

A primeira questão a ser ventilada diz respeito á docencia livre, por ser nesse carater que o interessado se apresentou em juizo. E essa docencia foi instituida obrigatoriamente, como o afirma o art. 74 do dec. n. 19.851, nestes termos: "A instituicão da docencia livre é obrigatoria em todos os institutos universitarios". E o dec. n. 23.609, de 1933, a mencionou expressamente, quando estabelecendo dois cursos seriados, o de bacharelado e o de doutorado, determinou que o ensino destes se fizesse em cursos normais equiparados. A expressão "a docencia livre destina-se a ampliar os cursos normais", não dá margem para duvidas. Relativamente ás catedras, a lei, em varias passagens, mastra tambem a sua existencia 
agora, as sobras dos vencimentos daqueles, quando licenciados.

Matava a lei, dessarte, com uma só cajadada, dois coelhos...

4. A avareza da lei não chegou, entretanto, ao ponto de não conceder direitos aos docentes livres. Conferiu-lhes o seu art. 172 os de:

a) ocupar o lugar de assistente, nas condições previstas no regulamento, ou o de chefe de clinica, de curso ou laboratorio, sem remuneração, quando propostos pelo respetivo professor;

b) fazer cursos equiparados ao curso oficial;

c) fazer cursos livres, obedecendo ás condições acima expostas;

d) concorrer á vaga de professor catedratico;

e) tomar assento na Congregação, quando substituindo o professor catedratico ou quando eleitos para representação da classe dos docentes livres, não podendo, entretanto, votar na escolha de professor catedratico.

Ficaram sendo os docentes livres, desde então e sem nenhuma duvida, os substitutos naturais e forçados dos professores catedraticos, nas suas licenças, e, de certo modo, os seus colaboradores na execução dos programas de ensino.

no curso de doutorado. As expressões "nenhuma das cadeiras do curso de doutorado" e "as aulas dos cursos de bacharelado e de doutorado" bem esclarecem a respeito. Aliás, o art. 36 do dec. n. 19.852 fala de modo expresso em professor catedratico no doutorado.

Tem-se assim a catedra e a docencia livre nesse curso. Ora, a cadeira de Direito Privado Internacional, que figurava no curso de bacharelado, veiu a ser colocada no de doutorado.

Ouça-se a exposição de motivos de Francisco Campos "esses principios podem e devem ser estudados de modo geral no direito privado, passando a constituir a cadeira de Direito Privado Internacional e, assim, mais bem colocada no curso de doutorado". E que aí foi collocada está a ver-se pelo art. 279 , § unico, do dec. $\mathbf{n}$. 19.852, quando menciona as materias da 1 . $^{2}$ secção no doutorado e inclúe a do Direito Privado Internacional.

Ha hoje projeto fazendo a sua transferencia para o curso de bacharelado. E só se transfere o que existe. Bem de ver ainda ter sido a Congregação quem aprovou a sugestão do Conselho Tecnico Administrativo para essa transferencia, segundo se evidencia da certidão de fls. 25. 
5. Estabelecendo as linhas do sistema universitario brasileiro, o dec. n. 19.851, de 11 de abril de 1931, esclareceu, no art. 48, variar o corpo docente dos institutos universitarios, na sua constituição, de acôrdo com a natureza do ensino a ser ministrado, mas formar-se, em moldes gerais, de professores catedraticos, auxiliares de ensino, docentes livres, e, eventualmente, de professores contratados e de outras categorias, na conformidade da natureza peculiar ao ensino de cada instituto universitario. Não introduziu inovação alguma. Manteve os professores catedraticos e, ao lado deles, os docentes livres, com a função de permitirem, pela ampliação em cursos equiparados aos normais, a capacidade didatica dos institutos universitarios e a de concorrerem, pelo tirocinio do magisterio, para a formação de professores.

Prevendo a hipotese, que se verificou, na generalidade dos institutos universitarios, de serem poucos os docentes livres que tivessem de ministrar o ensino em cursos equiparados, pois na maior parte deles se tolerou a falta de frequencia ás aulas, como normal e ostensivamente dispensada, tratou a lei de assegurar ao docente livre a oportunidade do seu tirocinio professoral.

Assente está, portanto, a existencia de catedras e docencias livre no curso de doutorado. E não se compreenderia que o docente livre deixasse de acompanhar a disciplina para a qual se habilitou.

Entende ainda a decisão recorrida que a substituição, onde ha simples comissão, se faz por professores designados pela Congregação e saídos do curso de bacharelado. Para tanto apoiou-se no art. 34 do dec. 19.852, que isto dispõe: "os professores do curso de doutorado poderâo ser designados pela Congregação dentre os professores catedraticos do curso de bacharelado". Mas o que se encontra nesse dispositivo nada mais é que uma simples faculdade só a ser usada em certas e determinadas condições. Quem o mostra é o proprio Conselho Universitario, nestas palavras: "Poderâo não tem significação imperativa e deve ser usada para os casos em que não haja outros direitos liquidos, isto é, para os casos de cadeiras novas e sem docentes livres, como se verifica no curso de doutorado, em que foram criadas diversas cadeiras e a situação financeira não comportava outras despesas".

Ai está a explicação do dispositivo.

Na lei fundamental do ensino se encontra, porém, o preceito regulador da materia. Ei-lo: "A substituição do professor cate- 
Por isso, no art. 76, expressamente reconheceu e conferiu ao docente livre o direito de:

a) realizar cursos equiparados;

b) substituir o professor catedratico nos seus impedimentos prolongados;

c) colaborar com o professor catedratico na realização dos cursos normais;

d) reger o ensino de turmas;

e) organizar e realizar cursos de aperfeiçoamento e de especialização relativos á disciplina de que é docente livre.

6. Trouxe, porém, o dec. n. 19.851, de 11 de abril de 1931, uma novidade: o curso de doutorado. Tratou dele o dec. n. 19.852, daquela mesma data, tanto ao dizer que o curso de Direito, na respetiva Faculdade, se daria em duas etapas: uma, de cinco anos - a do bacharelado; e outra de dois - a do doutorado; quanto ao determinar que poderiam os professores do curso do doutorado ser designados pelas Congregação dentre os professores catedraticos do curso de bacharelado.

Veiu dessa disposição o parecer n. 9, de 23 de abril de 1935, do Conselho Universitario, revogando a sua anterior decisão, de 18 de abril de 1934, afim de reconhecer á

dratico obedecerá a dispositivos dos regulamentos de cada um dos universitarios, devendo caber em primeiro lugar aos docentes livres e, na ausencia deles, aos professores contratados, auxiliares do ensino, ou ainda a professores de outras disciplinas do mesmo instituto, de acôrdo com a decisão do Conselho Tecnico Administrativo" (art. 66).

E logo a seguir: "ao docente livre será assegurado o direito de substituir o professor catedratico nos seus impedimentos prolongados" (art. 76).

Não se pode exigir mais clareza que a dos textos citados. Faculdade?

A resposta afirmativa está no art. 40 deste regulamento, assim concebido: "No caso de vacancia de qualquer cadeira ou nos impedimentos prolongados do respetivo professor, durante um periodo letivo ou mais, caberá a regencia a um dos docentes livres da mesma cadeira, não podendo o mesmo docente ser reconduzido no ano seguinte, salvo se a cadeira só tiver um docente livre".

A regra da substituição aí se encontra expressa. A faculdade da designação só se dá quando não ha docente livre. Existindo o 
Congregação da Faculdade da Universidade do Rio de Janeiro "a capacidade de designar livremente os professores do curso de doutorado, nos termos do art. 34 do dec. n. 19.852 , de 11 de abril de 1932, valendo o titulo de livre docente como simples indicação do direito dos candidatos a essa designação, mas sem nenhum direito legal a ela".

7. Instituindo o curso de doutorado, pensou a lei em ve-lo praticado sem despesa para o erario publico. Não mandou pôr em concurso as suas cadeiras. Tambem não designou professores para elas, especialmente. Nem se cogitou de verba para o pagamento dos seus vencimentos.

Como, em tais condições, dar vida ao curso de doutorado e eficiencia ao seu ensinamento?

Deixou isso a lei a cargo da Congregação de cada instituto, permitindo-lhe designar dentre os professores do curso do bacharelado os que se incumbissem de prelecionar as disciplinas do curso de doutorado; mas isso, e no texto ficou bem claro, "dentre os professores catedraticos do curso de bacharelado", tendo em vista, naturalmente, a especialidade cultural de cada um, quando não as afinidades da sua cadeira do bacharelado com as do doutorado.

docente, obrigatoria é a substituição por ele. Como então dar preeminencia ao dispositivo referente a faculdade sobre outro que, posteriormente, faz excluir essa faculdade pelo imperativo de seus termos?

Se o legislador quizesse adstringir-se á disposição facultativa, onde lograria aplicação a regra do imperativo?

Teria então dito: não havendo designação pela Congregação, a substituicão caberá em primeiro lugar ao docente livre. Mas o que está estabelecido é coisa diversa. O preceito especial não derrogou, pois, o geral, antes o explica.

$O$ que ha é simplesmente isto: não havendo substitutos obrigatorios, quais os mencionados pelos mesmos citados arts. 66 a 40 , respectivamente, dos decretos ns. 19.851 e 23.609, a Congregação poderá designar professores do curso de bacharelado. Nesta conformidade se decidiu, com a designação do docente livre DR. HAHNEMANN GUIMARÃEs; nesta conformidade pensam, e têm praticado, reitores, diretores e professores das nossas Universidades e Faculdades, como se vê da documentação dos autos. Por ultimo, atende a sentença recorrida que a vaga, não tendo sido provida, não pode ir para ela o docente, porquanto the seria dar a regencia permanente. 
Não cuidou a lei, certamente, por pouco provavel, com hipotese da inexistencia, em certo momento, de professor catedratico que não tivesse cadeira similar ou afim.

Um ponto, entretanto, desde logo ficou bem claro: o professor do curso de doutorado seria um professor catedratic do curso de bacharelado.

8. O caso em fóco, porém, é o de uma cadeira do curso de doutorado - a de Direito Privado Internacional, cujo professor catedratico se aposentou. Assiste, assim, ao docente livre de Direito Privado Internacional o direito de regencia da cadeira, enquanto se lhe não der titular definitivo? Poderá a Congregação designar outro professor, de outra disciplina do curso de bacharelado, o de Direito Publico Internacional, por exemplo, para rege-la? Ou está ela na obrigação de entrega-la ao docente livre de Direito Privado Internacional?

Não assiste a este, com efeito, direito algum á regencia definitiva da cadeira do curso de doutorado. Não póde ela designa-lo para tal, por faltar-lhe um requisito essencial, imposto pela lei: o de ser professor catedratico. Somente se compreenderia pudesse ele tomar-lhe a regencia como substituto do professor catedratico "nos seus impedimentos prolongados".

Isto, porém, não se dá. $O$ provìmento tem de ser realizado $\mathrm{e} o$ concurso já foi pedido.

A ser interpretado o art. 181, disposição transitoria, seria para conclusão diversa. Se não são providas as vagas dos professores transferidos para o curso de doutorado, essas vagas serão as do curso de bacharelado, donde houve a transferencia. 0 certo é que a lei fundamental deixa de estatuir esse não provimento e a transferencia da disciplina está para ser feita. Tudo se resolve, portanto, com a aplicação dos textos legais que regulam a materia. Trata-se assim de questão de direito, que de alta indagação não é. Motivo por que a idoneidade do meio usado não póde ser posta em duvida, uma vês que ha um direito preterido por ato de autoridade.

Conclúo o meu voto nestes termos: não se póde negar ao docente livre o direito de reger a cadeira, que se encontra vaga e para a qual se habilitou. E se o legislador declarou expressamente que "ao docente livre será assegurado o direito á substituição", essa segurança deverá ser feita pela justiça quando a negue a autoridade administrativa competente.

O direito é certo e incontestavel. A medida pleiteada, legitima. Concedo-a. 
Esse, porém, não foi o caso.

Aposentado o professor catedratico, a vaga, por essa aposentadoria aberta, não seria preenchida por concurso, por se não tratar de hipotese de concurso e de nomeação do professor catedratico pelo governo, na fórma da lei. A designação do professor seria, e ainda será, feita pela Congregação.

Ela não estaria, e não está impedida de designar o docente livre de Direito Privado Internacional. Deve ele ser mesmo o mais indicado, pela especialisação de seus conhecimentos, apurados em concurso da disciplina. Não lhe assiste, todavia, direito á cadeira, entre outros argumentos, "por não ser professor catedratico". Se lhe assistisse, isso importaria, pela natureza das coisas, numa investidura definitiva em cargo para que carecia do requisito essencial, o de ser professor catedratico.

9. A situação do docente livre não é, pois, a de titular da cadeira, para que fez concurso, no bacharelado e que, transferida para o doutorado, não foi provida, em visto do sistema legal de sua instituição. Deixou a lei inteiramente ao arbitrio da Congregação o prove-la: ou por um dos professores catedraticos do curso de bacharelado, ou por

O Sr. ministro Ataulpho de Paiva. - Sr. Presidente, apenas habilitado a julgar a materia através o longo, profuso e substancioso memorial apresentado pela parte, não tendo, portanto, conhecimento das peças que constituem os autos, era intenção minha de lhes solicitar vista, o que deixo de fazer diante a conveniente exposição ha pouco desenvolvida pelo ilustre advogado do impetrante e os expressivos fundamentos do voto do sr. Ministro Relator, que evidenciam, sem duvida alguma, tratar-se de um caso tipico, manifesto, absoluto, de mandado de segurança, alicerçado em direito, certo, liquido e incontestavel.

Ademais, todas as vezes que a situação do recorrente foi considerada pela Congregação, esta sempre lhe reconheceu o direito de ocupar, interinamente, a cadeira em litigio. Jamais houve um unico parecer ou decisão contraria a esse objetivo, e tambem não consta do processo, do relatorio e do voto proferido pelo sr. Ministro Relator qualquer documento ou despacho capaz de denunciar, siquer de longe, a mais leve suspeita, o menor desentendimento entre os professores que fazem parte da Congregação no sentido de negar o direito do impetrante. Todos a una voce o proclamaram sempre, quaisquer que fossem as circunstancias, ao Professor Harowdo VAL- 
professor estranho para isso contratado, ou por docente livre da mesma cadeira se, como no caso de que se trata, já existente.

Se tivesse este o direito certo e incontestado de prelecionar a disciplina, mercê do seu titulo de livre docente, em professor catedratico ele se transmudaria, sem que o fosse: só professores catedraticos do curso de bacharelado é que podem, pela Congregação, ser designados para a regencia das cadeiras do curso de doutorado.

10. Divirjo, com magua, dos pareceres, que me foram apresentados por copias, com este devolvidas, dos eminentes professores Conde de Affonso Celso, Manuel Cicero e F. Mendes Pimentel: não tem o docente livre Haroldo Valladão o direito certo e incontestado de assumir a regencia da cadeira de Direito Privado Internacional do curso de doutorado da Faculdade de Direito da Universidade do Rio de Janeiro. Não tem tal direito, ainda que interinamente, porque a interinidade, na hipotese, constituiria, para ele, uma vitaliciedade, por não ter a lei dado provimento definitivo ás cadeiras do curso de doutorado. Todas elas serão regidas, interinamente, provisoriamente, por professores catedraticos do curso de bacharelado, escolhidos e designados pela Congregação. Esta é que poderá, sem duvida, dados

LADÃo cabe reger a cadeira de Direito Privado Internacional, interinamente. Tanto assim que era o escolhido para as substituições decorrentes do afastamento, por qualquer motivo, do catedratico da materia.

O parecer da comissão nomeada depois do concurso a que submeteu o requerente, foi unanime em declarar legitimo o seu direito a ocupar o cargo efetivamente. $\mathbf{E}$ foi efetivado.

Sr. Presidente, neste momento, não desejo discutir o fato posterior da Congregação, reformando ou revogando a deliberação que tomara. Entretanto, forçoso é confessar, não surgir lei alguma, mesmo no periodo do governo discricionario, modificando o regime em vigor, que autorizasse a Congregação a seguir orientação diversa da adotada até á partida do requerente para a Europa. A sua situação manteve-se inalteravel.

Os casos da cadeira de Direito Romano, sendo nomeado o Professor HahnemanN, o da transferencia do Professor Francisco Campos e, tambem, da transferencia do Professor Joaquim Pimenta, da Faculdade de Recife, deixam bem claro o unico argumento em que se podia prestar atenção, qual o de saber se o professor do curso de bacharelado póde lecionar, interinamente, materias do programa 
o grande merecimento e o tirocinio, já revelados e indiscutiveis, daquele docente livre, designa-lo, como já o tem feito, para a regencia daquela cadeira, em que se tem mostrado eximio.

Não perderá a Congregação, por certo, de vista o dispositivo legal, mercê do qual ficaram os docentes livres, tambem, com a atribuição de organizar e realizar cursos de aperfeiçoamento e de especialização relativos á disciplina de que são docentes livres.

Isso, á margem do curso de bacharelado. Porque não os aproveitar, pois, no de doutorado, quando inexistirem professores da cadeira do bacharelado, como no caso sujeito?

Rio de Janeiro, 17 de junho de 1935.

do curso de doutorado. Mas este argumento não subsiste, porque as substituições processam-se do mesmo modo num e noutro curso, e tanto isso é verdade que o Poder Executivo não hesitou em efetuar as transferencias a que aludo.

Sr. Presidente, apezar de reconhecer o subido valor dos dois professores que disputam esta livre docencia e os inestimaveis serviços á causa do ensino em nosso país, o meu espirito não hesita em aceitar as razôes apresentadas pelo requerente e os argumentos constantes do voto do sr. Ministro Relator, tão perfeitos e tão cristalinos são os dispositivos legais que regem a especie.

Voto com o sr. Ministro Relator, concedendo o mandado de segurança.

O SR. Ministro Bento De Faria. - iSr. Presidente, vencido na preliminar, quanto á incompetencia do juizo, tambem concedo o mandado de segurança.

O Sr. Ministro Arthur Ribeiro. - Sr. Presidente, concedo o mandado de segurança. A duvida que assaltou o espirito do Ministro Costa Manso tambem preocupou o meu. Se o Dr. Raul PederneiRAS tivesse sido provido definitivamente na cadeira, não se poderia cogitar de substituição. Desde, porém, que não o foi, a substituiçẫo cabe por força do regulamento ao DR. Haroldo Valladĩo.

Este é o meu voto". 